\title{
Estado de conservação e qualidade da água em uma bacia hidrográfica periurbana na Amazônia Central
}

\author{
Conservation status and water quality in a periurban watershed in Central Amazon
}

\author{
J. S. da Costa ${ }^{1 *}$ L. de S. Rodrigues ${ }^{1}$; A. G. C. da Silva ${ }^{1} ;$ T. da C. Reis ${ }^{2}$; M. da G. \\ G. de Melo'; M. A. R. Liberato ${ }^{1}$ \\ ${ }^{1}$ Universidade do Estado do Amazonas - UEA, Escola Normal Superior - ENS, 69850-000, Manaus-AM, Brasil \\ ${ }^{2}$ Universidade do Estado do Amazonas - UEA, Escola Superior de Tecnologia - EST, 69850-000, Manaus-AM, Brasil
}

*jamersonjsc@yahoo.com

(Recebido em 11 de fevereiro de 2021; aceito em 23 de setembro de 2021)

\begin{abstract}
As bacias florestadas geralmente estão associadas à melhor qualidade da água, em comparação com usos antropogênicos. Contudo, a multiplicidade de variáveis e interações torna essa relação bastante complexa, sobretudo na Amazônia, onde os sistemas hídricos são interinfluenciáveis. Este trabalho objetivou classificar o uso e cobertura da terra e o estado de conservação da Bacia Hidrográfica do Tarumã-Açu, na Amazônia Central, bem como analisar sua correlação com os parâmetros físico-químicos (temperatura, $\mathrm{pH}$, condutividade elétrica, oxigênio dissolvido, sólidos totais dissolvidos e turbidez) de qualidade da água em pontos preservados e alterados. Os valores foram comparados com a Resolução CONAMA 357/2005 e com fatores ambientais (cota e pluviosidade). Os resultados mostraram uma bacia bastante fragmentada e em estado regular de degradação, apesar de sua cobertura predominantemente florestal. Constatou-se, ainda, em média, boa qualidade da água, compatível com os parâmetros normativos para a Classe 2, embora para as zonas de influência antrópica, a diminuição da cota e da capacidade de autodepuração reduz a qualidade. Não houve relação de linearidade entre os parâmetros avaliados e o estado de conservação da bacia, sugerindo a existência de mais fatores de ruptura dessa relação. Assim, é necessário e desafiador para os gestores conhecer, de forma holística, a dinâmica eco-hidrológica da bacia e integrá-la às políticas e planos. Palavras-chave: recursos hídricos, uso da terra, floresta.
\end{abstract}

Forested basins are generally associated with better water quality, compared to anthropogenic uses. However, the multiplicity of variables and interactions makes this relationship quite complex, especially in the Amazon, where water systems are inter-influential. We classified the land use and cover and the conservation status of the Tarumã-Açu Basin, in Central Amazon, as well as to analyze its correlation with the physical-chemical parameters (temperature, $\mathrm{pH}$, electrical conductivity, oxygen dissolved, total dissolved solids and turbidity) of water quality at preserved and altered sites. The values were also compared with CONAMA Resolution 357/2005 and with environmental factors (quota and rainfall). The results showed a very fragmented basin and regular degradation status, despite its predominantly forest cover. We found good water quality, compatible with Class 2 normative parameters, although for the areas of anthropic influence the reduction of the quota and the capacity for self-purification reduces the quality. There was no linearity relationship between the parameters evaluated and the conservation status of the basin, suggesting the existence of more rupture factors in this relationship. Thus, it is necessary and challenging for managers to know holistically the eco-hydrological dynamics of the basin and integrate it with policies and plans.

Keywords: water resources, land use, forest.

\section{INTRODUÇÃO}

As modificações no uso da terra têm afetado os processos biológicos e biogeoquímicos, incluindo o ciclo hidrológico e a quantidade e qualidade dos recursos hídricos [1]. Apesar de não enfrentar escassez, em termos de quantidade, o uso desordenado da terra, com perda florestal, impacta cada vez mais a qualidade das águas e a capacidade de resiliência dos sistemas ecohidrológicos nas bacias amazônicas [2]. Portanto, a gestão dos recursos gerados por ecossistemas aquáticos e terrestres deve ocorrer de maneira integrada, o que constitui um desafio, já que as interações entre água e floresta são bastante complexas e envolvem uma série de variáveis [3].

No entanto, muitos dos processos naturais relacionados com a água na paisagem não fazem parte da agenda dos formuladores de políticas públicas nem do público em geral, que tendem a 
ver essa questão como algo reservado à academia. Além disso, as questões hídricas são, quase exclusivamente, analisadas a partir da perspectiva dos recursos hídricos, sem que haja projeção de objetivos e estratégias capazes de balancear os diversos aspectos da paisagem, numa abordagem eco-hidrológica e social de desenvolvimento, e com base em uma gestão integrada da água e da terra.

A influência das florestas sobre a qualidade das águas dos canais fluviais envolve uma diversidade de processos, desde a absorção direta e ciclagem de íons pela vegetação ripária, até a promoção da estabilidade dos solos, redução da energia do escoamento superficial e das águas pluviais sobre o solo, além de minimizar a entrada, por lixiviação, de sedimentos e poluentes/contaminantes, associados ou não a resíduos sólidos [3]. Como resumem Brogna et al. (2017) [4], as florestas e os solos florestais promovem a recepção, o processamento e a transferência de água, com menos sedimentos e menos nutrientes.

Embora haja muito a ser esclarecido com relação ao impacto da redução da cobertura vegetal sobre o aumento no fluxo de água em diferentes escalas espaço-temporais [3, 5-7], quando se trata dos efeitos deletérios da redução/fragmentação florestal e dos usos antropogênicos da terra sobre a qualidade da água, o consenso é praticamente unânime, como afirmam Lawrence e Vandecar (2015) [8], Mekonnen e Hoekstra (2016) [9]. Esse conhecimento deve, inclusive, ajudar na definição de metas e na avaliação da eficácia de estratégias de gestão da qualidade dos recursos hídricos [10], itens indispensáveis à implementação dos instrumentos de gestão - Enquadramento e Plano de Recursos Hídricos - previstos na Lei no $9.433 / 97$ [11].

O uso e a ocupação desordenada da terra geram, além das situações de conflito nas Áreas de Preservação Permanente (APPs), o incremento de sedimentos e nutrientes, com assoreamento e eutrofização dos canais, respectivamente; a perda de habitats, tanto nos ambientes aquáticos como terrestres; a poluição/contaminação, pelo lançamento de efluentes domésticos e industriais e resíduos sólidos; alteração do regime hidrológico e a ocorrência de eventos extremos; e a perda da capacidade de autodepuração dos corpos d'água e de resiliência da paisagem natural da bacia [12].

No caso de pequenas bacias, sobretudo aquelas situadas em zona urbana e periurbana, como a Bacia Hidrográfica do Tarumã-Açu (BHTA), a vulnerabilidade às alterações na cobertura e uso da terra é maior e, portanto, essas unidades territoriais também constituem importantes unidades de planejamento e gestão [13]. A BHTA, apesar do potencial ecoturístico, apresenta uma série de conflitos ambientais, decorrentes dos múltiplos usos de suas águas e do processo desordenado de expansão urbana e desenvolvimento socioeconômico, incluindo atividades ilegais como a produção de carvão e extração de minerais não metálicos [14].

O avanço e a intensificação das transformações antrópicas têm fragmentado a paisagem natural da BHTA e reduzido grandes áreas de floresta a pequenas manchas isoladas, além de impactar negativamente a qualidade das águas dos canais de drenagem, conforme Vasconcelos (2012) [15], Braga et al. (2012) [14], Santana e Barroncas (2007) [16] e Santos et al. (2006) [17]. Nesse contexto, o presente estudo objetiva avaliar o impacto das transformações antrópicas na qualidade da água da BHTA, por meio da classificação das áreas de uso e cobertura da terra e do estado de conservação da bacia, e da análise de parâmetros físico-químicos de qualidade da água; de modo a subsidiar as discussões e o encaminhamento das ações de implantação do plano de gestão da bacia.

\section{MATERIAL E MÉTODOS}

\section{Área de estudo}

A Bacia Hidrográfica do Tarumã-Açu está localizada na Região Central da Amazônia, à margem esquerda do Rio Negro, a montante da cidade de Manaus (Figura 1); e constitui uma das quatro grandes bacias hidrográficas sobre as quais está assentada a capital amazonense [13]. É uma bacia de quinta ordem, com área total de 137.273 hectares, formada pelo rio Tarumã-Açu (canal principal) e seus tributários, que ocupam, aproximadamente, $12 \%$ do território do município $[15,18]$. 


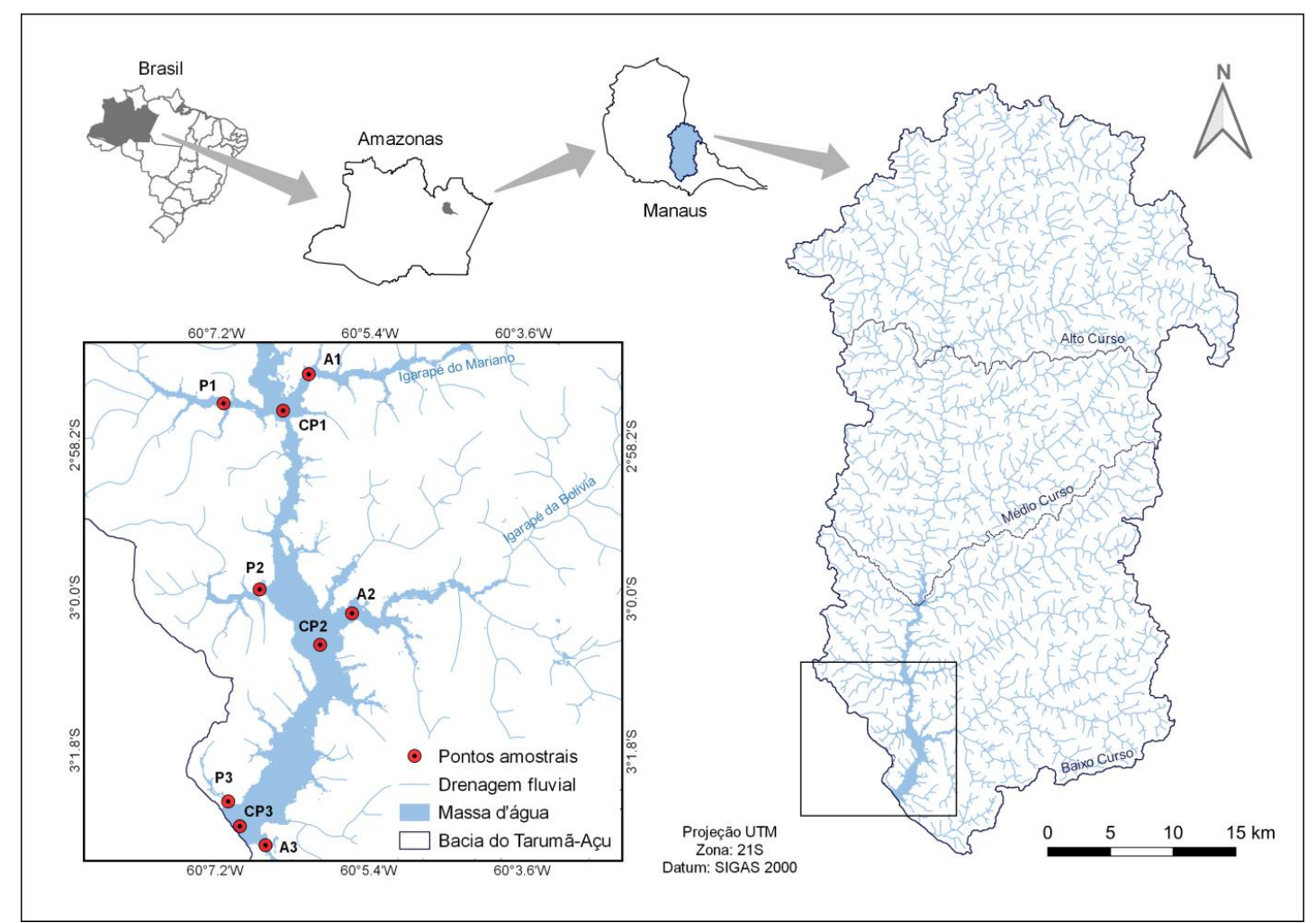

Figura 1 - Bacia Hidrográfica do Tarumã-Açu e distribuição, no baixo curso, dos pontos de amostragem dos parâmetros físico-químicos de qualidade da água. A: pontos alterados (antropizados); P: pontos preservados; e CP: pontos distribuídos no canal principal.

De acordo com Costa et al. (2013) [18], sua morfometria ampla e alongada (fator de forma $=$ 0,41 ) e sua drenagem pobre sugerem uma resposta hidrológica lenta, com pouca tendência à ocorrência de enchentes. Por outro lado, a pouca ou nenhuma sinuosidade favorece o carreamento de sedimentos e o surgimento de processos erosivos, principalmente em áreas sem cobertura vegetal [18]. As texturas argilo-arenosa do Latossolo Amarelo, nos platôs, areno-argilosa do solo Podzólico Vermelho-Amarelo das encostas, próximo aos baixios, e arenosa do solo Areno Hidromórfico, nos baixios, também facilitam a ocorrência de erosão nas áreas descobertas [19, 20].

Derivados da Formação Alter do Chão, os solos da bacia são predominantemente cobertos por vegetação do tipo Floresta Ombrófila Densa, podendo ser encontradas, ainda, tipologias típicas de Floresta Ombrófila Aberta, Floresta Aluvial Periodicamente Inundada (Floresta de Igapó), Campinarana e áreas de uso antropogênico (urbana, agroindustrial e comunidades tradicionais), conforme Vasconcelos (2012) [15]. A Formação Alter do Chão, cretácea ou cenozoica, forma o assoalho da planície holocênica central da Bacia Amazônica e é composta por rochas siliciclásticas (arenitos avermelhados, argilitos, siltitos e conglomerados), depositadas em sistema fluvial e lacustre/deltaico, em condições de paleoclima quente com semiaridez dominante [18, 20]. O clima superúmido, segundo o Índice de De Martonne, com três meses de seca suave a moderada (julho, agosto e setembro) e seis meses (dezembro a maio) de maior umidade e pluviosidade; e junho e outubro como meses de transição entre os períodos; e a temperatura média anual de $27^{\circ} \mathrm{C}[19,21]$ são características das florestas tropicais.

\section{Classificação do uso e cobertura da terra}

Para a classificação da cobertura e uso da terra, utilizou-se imagem Landsat 8, sensor OLI, com resolução espacial de $30 \mathrm{~m}$, disponibilizada pelo Instituto Nacional de Pesquisas Espaciais (INPE - http://www.dgi.inpe.br). Selecionou-se a imagem mais recente (data de passagem em 27 de julho de 2016) sem cobertura de nuvens e/ou sombras sobre a região de interesse. Essas são 
imagens multiespectrais e largamente utilizadas nesse tipo de mapeamento, conforme Figur e Reis (2017) [22] e Ribeiro et al. (2017) [23]. Os dados vetoriais da bacia foram adquiridos junto ao grupo de pesquisa Geotecnologia e Análise da Paisagem (GEOTAP), da Escola Normal Superior (ENS), da Universidade do Estado do Amazonas (UEA).

$\mathrm{Na}$ etapa de pré-processamento, as composições das cenas foram geradas a partir das bandas espectrais 4 (vermelho), 5 (infravermelho próximo) e 6 (infravermelho médio), geralmente adotadas em estudos de cobertura vegetal, devido às diferentes respostas espectrais da vegetação [24]. O empilhamento, recorte e composição falsa cor das bandas 456/RGB foi realizado no software QGIS 3.4.5 (Madeira). Na sequência, procedeu-se com a classificação supervisionada no software SPRING 5.5.6 [25], segundo o método de segmentação e classificação de regiões Bhattacharrya, aceitação de $95 \%$ [23].

A classificação utilizando técnicas de geoprocessamento torna o processo menos subjetivo e potencialmente reproduzível [26]. Foram definidas seis classes, com base no Manual Técnico de Uso da Terra [25]: (1) florestal (formações florestais primárias ou secundárias); (2) campestre (vegetação não florestal, natural ou antropizada); (3) urbanizada (áreas urbanas, não vegetadas, integradas ou isoladas); (4) descoberta (ambientes naturais ou antropizados, com vegetação bastante esparsa ou sem vegetação); (5) mineração (áreas de exploração de minerais metálicos ou não metálicos); e (6) água (corpos d'água continentais naturais e artificiais).

Conforme Rusca et al. (2017) [27], no pós-processamento, foi inicialmente verificada a acurácia dos dados, segundo o coeficiente Kappa $(\mathrm{K}=0,9861)$, categorizado por Landis e Koch (1977) [28] como perfeito. Posteriormente, ocorreu a reambulação dos dados, a partir de pontos georreferenciados, distribuídos ao longo da bacia em função das condições de acessibilidade [29]. Por fim, foi feita a vetorização e quantificação das classes temáticas e elaboração do layout final, seguindo a cartela de cores recomendada no Manual Técnico de Uso da Terra [25].

\section{Caracterização do estado de conservação da bacia}

Com base nas classes de uso e cobertura da terra, calculou-se o Índice de Transformação Antrópica (ITA), Equação 1, para caracterização do estado de conservação da BHTA. O ITA foi desenvolvido por Lémechev (1982) [30] e é aplicado em estudos ambientais para mensurar a pressão antrópica sobre a paisagem [23, 26, 31-33]. Quando combinado com técnicas de geoprocessamento, esse índice possibilita a avaliação espacial da situação antropogênica local [34].

$$
I T A=\sum(\% \text { USO } \times \text { PESO }) / 100
$$

Onde: $I T A=$ Índice de Transformação Antrópica; $U S O$ = área (em valores percentuais) da classe de uso e cobertura da terra; $P E S O=$ peso dado aos diferentes tipos de uso e cobertura quanto ao grau de alteração antrópica (varia de 1 a 10, em que 10 indica as maiores pressões).

Para definição dos pesos atribuídos às classes de uso e cobertura da terra, aplicou-se a Técnica Delphi. Essa técnica possibilita o estabelecimento de consenso a partir da visão multidisciplinar de especialistas $[23,35]$. A classificação do nível de transformação antrópica da bacia foi definida conforme quartis propostos por Cruz et al. (1998) [36], variando de pouco a muito degradada.

\section{Parâmetros físico-químicos de qualidade da água}

Como indicado na Figura 1, foram definidos nove pontos amostrais, considerando-se o princípio sistêmico das bacias hidrográficas, conforme Menezes et al. (2016) [37] e Santos et al. (2017) [38]. Seis pontos distribuídos nos exutórios de afluentes do rio Tarumã-Açu, sendo três pontos alocados à margem direita (cobertura predominantemente florestal) e três pontos à margem esquerda (uso antrópico), configurando os pontos de amostragem em trechos preservados $(\mathrm{P})$ e alterados (A). Os pontos restantes foram alocados na calha principal (CP) da bacia, o rio TarumãAçu, no intuito de verificar o reflexo dessas contribuições na água do canal. A distribuição dos 
pontos ocorreu a partir da porção média da massa d'água em direção ao exutório, no baixo curso da bacia, em razão da acessibilidade.

As análises foram realizadas bimestralmente, entre set./2019 e jul./2020, compreendendo os períodos chuvoso e de estiagem, bem como, de enchente e vazante. Conforme preconiza o Guia Nacional de Coleta e Preservação de Amostras [39], para cada ponto de amostragem, determinouse in situ: temperatura da água (TA), potencial hidrogeniônico ( $\mathrm{pH}$ ), condutividade elétrica (CE), oxigênio dissolvido (OD), sólidos totais dissolvidos (STD), utilizando sonda multiparâmetros (Hanna - HI98194); e turbidez (TB), com o auxílio de turbidímetro (Instrutherm - TD 300).

\section{Análise dos dados}

Com exceção dos parâmetros TA e CE, que não possuem valores referenciais legalmente definidos, os demais resultados foram comparados com os limites estabelecidos pela Resolução CONAMA n ${ }^{\circ}$ 357/2005 [40], que define os critérios de classificação e usos de corpos de água no Brasil. A variabilidade dos resultados dos parâmetros para cada ponto de amostragem está apresentada em gráficos do tipo Box Plot. O teste de normalidade de Shapiro-Wilk $(\mathrm{p}>0,05)$ foi aplicado para avaliar a distribuição dos dados [41, 42].

Utilizou-se o coeficiente de correlação de Spearman na verificação da relação entre os parâmetros físico-químicos e destes com variáveis ambientais (cota e pluviosidade) [41, 42]. Já as análises multivariadas de Cluster (hierarchical Cluster analysis - HCA) e de componentes principais (principal component analysis - PCA) foram empregadas para averiguar o grau de similaridade entre os pontos amostrais (preservados e alterados), e sua correlação com os parâmetros de qualidade de água [37, 43]. Todas as análises estatísticas foram realizadas com o auxílio do software StatSoft Statistica 12.5.

\section{RESULTADOS E DISCUSSÃO}

No conjunto da paisagem, 64,78\% da área da bacia corresponde à cobertura florestal, o equivalente a 88.921 ha. Bastante fragmentada, as maiores manchas de floresta estão distribuídas na região da cabeceira e na margem direita da bacia, além da Reserva Florestal Adolpho Ducke (RFAD), no baixo curso. Apesar da predominância florestal, 31,91\% de sua área já sofreu algum tipo de transformação antropogênica, resultando em estado regular de conservação (ITA = 2,73). As proporções e áreas das classes de uso e cobertura da terra, sua distribuição, bem como o estado de conservação, da BHTA e seus segmentos estão apresentados na Tabela 1 e na Figura 2A.

Tabela 1 - Distribuição das classes de uso e cobertura da terra (em ha e \%) e o estado de conservação, com base no Índice de Transformação Antrópica (ITA), na bacia do Tarumã-Açu e seus segmentos.

\begin{tabular}{|c|c|c|c|c|c|c|c|c|}
\hline \multirow{2}{*}{ Classes } & \multicolumn{2}{|c|}{ BHTA } & \multicolumn{2}{|c|}{ Baixo curso } & \multicolumn{2}{|c|}{ Médio curso } & \multicolumn{2}{|c|}{ Alto curso } \\
\hline & Área & $\%$ & Área & $\%$ & Área & $\%$ & Área & $\%$ \\
\hline Área Florestal & 88.921 & 64,78 & 22.570 & 43,49 & 22.756 & 64,48 & 45.543 & 86,94 \\
\hline Área Campestre & 19.947 & 14,53 & 9.776 & 18,84 & 6.142 & 17,40 & 4.077 & 8,14 \\
\hline Área Urbanizada & 5.587 & 4,07 & 5.408 & 10,42 & 73 & 0,21 & 65 & 0,13 \\
\hline Área Descoberta & 17.408 & 12,68 & 9.981 & 19,23 & 5.454 & 15,45 & 2.000 & 3,99 \\
\hline Área de Mineração & 869 & 0,63 & 636 & 1,23 & 145 & 0,41 & 101 & 0,20 \\
\hline Água & 4.541 & 3,31 & 3.527 & 6,80 & 720 & 2,04 & 299 & 0,60 \\
\hline ITA & \multicolumn{2}{|c|}{2,73} & \multicolumn{2}{|c|}{3,96} & \multicolumn{2}{|c|}{2,64} & \multicolumn{2}{|c|}{1,51} \\
\hline $\begin{array}{c}\text { Estado de } \\
\text { conservação }\end{array}$ & \multicolumn{2}{|c|}{ Regular } & \multicolumn{2}{|c|}{ Regular } & \multicolumn{2}{|c|}{ Regular } & \multicolumn{2}{|c|}{ Pouco degradada } \\
\hline
\end{tabular}

Analisando em escala menor, verifica-se que o baixo curso apresenta o pior estado de conservação, embora seja categorizado como regular (ITA $=3,96)$. Esse segmento da bacia possui a menor proporção de cobertura florestal $(43,49 \%)$, além de concentrar praticamente a totalidade da área urbanizada (5.408 ha) e mais de $70 \%$ das áreas de mineração. Os resultados são 
compatíveis com o estudo realizado por Vasconcelos (2012) [15], que registrou, no ano de 2016, $44 \%$ de cobertura florestal no "setor sul" da BHTA, que corresponde ao baixo curso mais uma pequena porção do médio curso. Numa análise comparativa com o ano de 2007, houve redução de $38,9 \%$ da área florestal [15].

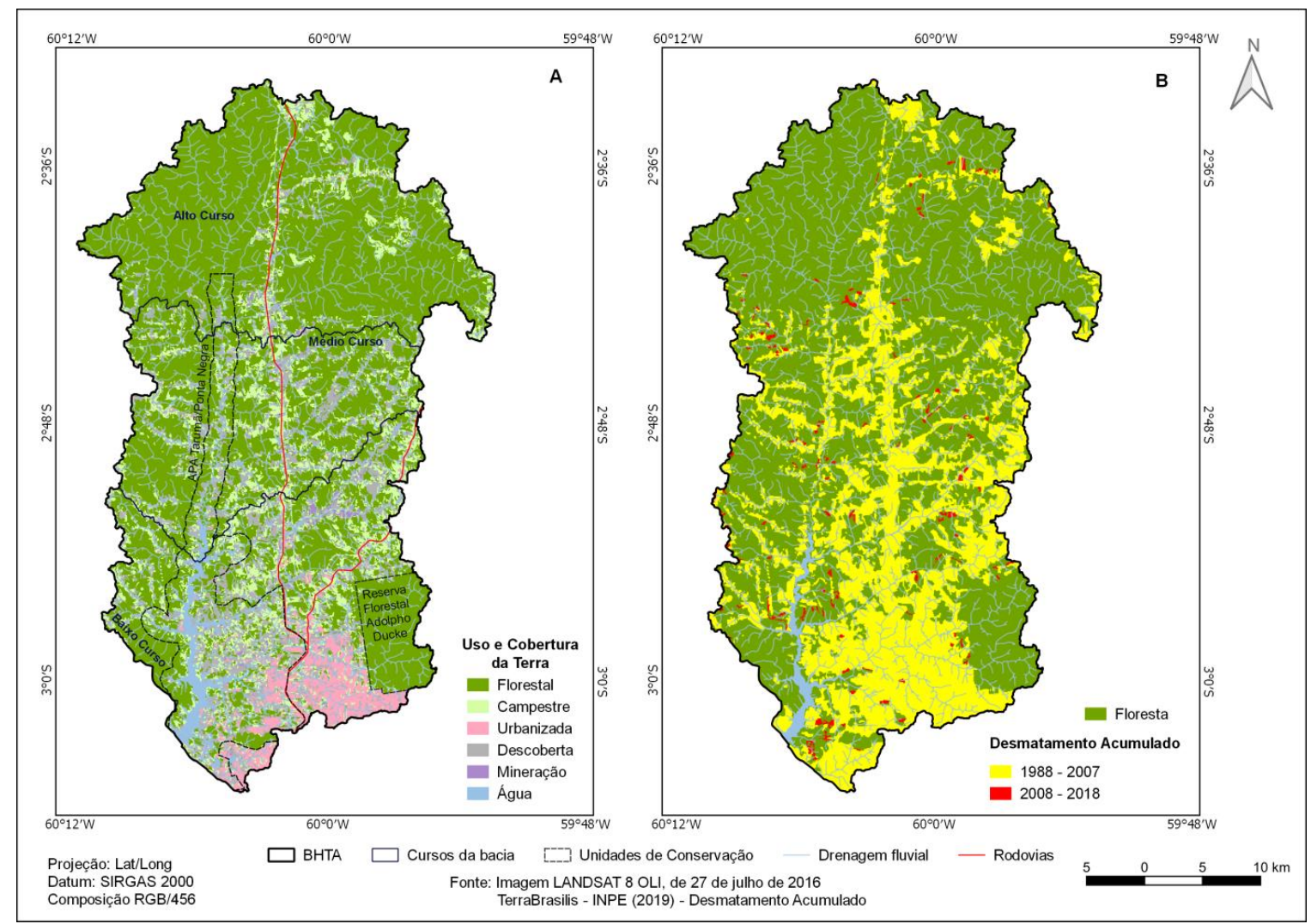

Figura 2 - Uso e cobertura da terra (A), em 2016; e desmatamento acumulado (B), entre 1988 e 2018, na Bacia Hidrográfica do Tarumã-Açu.

O médio curso, também classificado como regular, exibe ITA $=2,64$, em razão da perda de sua cobertura florestal. Em termos proporcionais, se assemelha ao baixo curso no que se refere aos percentuais de área exposta e vegetação campestre, resultado da abertura de ramais e vicinais, da consequente ocupação e do desenvolvimento de atividades de lazer (balneários) e agropecuárias, sobretudo nas comunidades que integram o Assentamento Tarumã-Mirim, implantado, em 1992, pelo Instituto Nacional de Colonização e Reforma Agrária (INCRA), à margem direita da bacia e destinado à agricultura familiar.

$\mathrm{O}$ alto curso, classificado como pouco degradado (ITA $=1,51$ ), possui uma matriz predominantemente florestal (86,94\%), embora sua paisagem apresente alterações margeando a rodovia BR-174, com disjunções em direção à margem esquerda da bacia. Miranda et al. (2019) [33] também mapearam áreas pouco degradadas associadas à região de cabeceira, na bacia do Rio Jauru (MT). Segundo Ribeiro et al. (2017) [23], a abertura de acessos é determinante para a expansão do desmatamento e da ocupação de determinada região. De acordo com Carvalho e Molinari (2014) [44], associada à perda de vegetação, a construção da BR-174 tem levado ao surgimento e agravamento de processos erosivos, dos quais dez são do tipo voçoroca.

Dessa forma, as estratégias de planejamento e gestão da BHTA devem sopesar essa dinâmica de transformação da paisagem em direção à cabeceira, tendo em vista seu importante papel na sustentabilidade do sistema eco-hidrológico da bacia, em razão do número de nascentes e do estado de degradação dos outros segmentos. A identificação do direcionamento nos usos da terra constitui ferramenta de diagnóstico e indica as regiões que necessitam de maior atenção dos gestores $[26,35]$. 
Como afirmam Almeida e Vieira (2019) [31], Erdogan (2017) [45] e Ribeiro et al. (2017) [23], o aumento do nível de transformação antrópica acelera os processos de degradação ambiental da bacia e reduz a capacidade de suporte da paisagem. Daí a necessidade de monitoramento do avanço do desmatamento nas áreas classificadas como pouco degradadas, evitando a rápida degradação desses ambientes. Conforme demonstraram Cocco et al. (2015) [32] e Pérez e Carvalho (2012) [46], essa piora do ITA, com mudança de classificação, pode ocorrer em pouco tempo $(<10$ anos $)$.

Dados do INPE (2019) [47] apontam um desmatamento acumulado de 45.361 ha na BHTA, no período de 1988 a 2018 (Figura 2B), o equivalente a 33,04\% da área total da bacia, corroborando com os dados desta pesquisa, quanto à perda da cobertura natural da bacia. Mais de 97\% desse desmatamento ocorreu até 2007. Uma parte dessas áreas desflorestadas foi substituída por usos antrópicos (urbanização, mineração, agropecuária) e a outra por vegetação secundária, em diferentes estágios de regeneração.

O monitoramento da vegetação secundária é outro aspecto fundamental no acompanhamento das transformações antrópicas em bacias hidrográficas, já que, de acordo com Farinaci e Batistella (2012) [48], denota a transição florestal e indica reversão na tendência de desmatamento. Estudos sobre a vegetação secundária na Amazônia Legal brasileira demonstram que, à medida que a ocupação de uma região se consolida, o desmatamento e o uso da terra para fins agropecuários se intensificam, com consequente diminuição na formação de vegetação secundária $[49,50]$.

Diferentemente de Gouveia et al. (2013) [50], Guglielmeli et al. (2018) [26] e Rodrigues et al. (2014) [51], que, ao estudarem bacias periurbanas, registraram uma concentração das áreas pouco degradadas nas APPs, a perda de cobertura florestal na BHTA está associada, justamente, à ocupação das margens dos corpos d'água, seja para fins habitacionais, recreacionais e/ou comerciais. Esse padrão é apontado por Almeida et al. (2010) [49] também para a calha do médio e do baixo Amazonas, em razão da ocupação por populações ribeirinhas, que praticam agricultura de subsistência.

A perda de floresta nativa, especialmente nas zonas ripárias, traz consequências negativas para a qualidade e disponibilidade dos recursos hídricos, além de comprometer os serviços ambientais e afetar diretamente a diversidade biológica [52]. Na BHTA, considerada de interesse ecológico e região turística da capital, e cujo desenvolvimento socioeconômico está vinculado ao seu caráter paisagístico, a redução contínua de florestas pode reduzir o potencial ecoturístico.

Mesmo a delimitação de unidades de conservação (UCs), como as Áreas de Proteção Ambiental Margem Esquerda do Rio Negro - Setor Tarumã-Açu/Tarumã-Mirim (APAME) e Tarumã/Ponta Negra (APATP), não tem sido suficiente para conter a transformação da paisagem, especialmente na região do baixo curso, onde os fragmentos florestais configuram pequenas manchas distribuídas numa matriz antropizada. Apesar de criadas em 1995 e 2008, respectivamente, essas UCs não possuem planos de gestão/manejo implementados, que direcionem ações de conservação e restauração [53].

Para Barlow et al. (2016) [54] e Pereira e Vieira (2019) [34], a simples criação de áreas protegidas, sem a definição e a efetivação de estratégias de gestão, que visem o monitoramento do desmatamento e o ordenamento do uso dos recursos naturais, o fortalecimento dos sistemas de governança e a promoção de arranjos produtivos sustentáveis, pode não ser capaz de barrar o avanço das transformações antrópicas. É o que se constata na bacia do Tarumã-Açu. Segundo Brown et al. (2015) [55], não são lugares ou espécies que tornam a conservação efetiva, mas a definição de objetivos claros e a priorização de ações.

Na margem direita há, ainda, uma sobreposição das APAME e APATP com o Assentamento Tarumã-Mirim. Tal qual observado por Costa et al. (2012) [19], o desflorestamento na margem direita da bacia está diretamente ligado à implantação e expansão das comunidades ali assentadas, o que revela o conflito resultante da sobreposição de áreas de assentamento com UCs. Os estudos de Paiva et al. (2019) [56], Pereira e Vieira (2019) [34] e Da Silva et al. (2019) [57] também registraram a perda de cobertura florestal em áreas protegidas de bacias amazônicas, associada a projetos agropecuários e à extração ilegal de madeira.

Nessa região, as classes campestre e solo exposto correspondem, basicamente, às atividades agropecuárias e extração ilegal de madeira para produção de carvão. A exposição fragiliza o solo da bacia, suscetibilizando-o à ocorrência de processos erosivos, de assoreamento e de perda da 
qualidade hídrica, como apontam Oliveira e Nunes (2015) [58], Silva et al. (2018) [59] e Da Silva et al. (2019) [57]. No caso das áreas de mineração, o potencial erosivo da própria atividade, agravado pela condição pluviométrica da região, reduz a capacidade de resiliência do ambiente, requerendo medidas mitigadoras mais complexas, custosas e de resposta mais lenta, para recuperar seu potencial natural [60].

Nos canais fluviais onde o tráfego de embarcações é intenso, somado à retirada da vegetação ripária, as ondas (banzeiros) artificialmente provocadas acarretam o desbarrancamento das margens (especialmente entre os pontos CP2 e CP3), formando o que Carvalho e Cunha (2011) [61] chamam de "falésia fluvial". Labadessa (2014) [62], Marques e Carvalho (2019) [63] e Queiroz e Tomaz Neto (2019) [64] igualmente apontaram a influência dos banzeiros para o surgimento ou agravamento de erosões laterais fluviais em trechos dos rios Madeira (RO), Amazonas (AM), Solimões e Negro (AM), respectivamente.

\section{Qualidade da água em pontos preservados e alterados}

Os resultados dos parâmetros de qualidade da água são apresentados na Tabela 2 e Figura 3. A temperatura da água manteve-se dentro da faixa dos $29,31^{\circ} \mathrm{C}$ e $36,07^{\circ} \mathrm{C}$, sendo que os pontos preservados (P1, P2 e P3) registraram os maiores valores médios, respectivamente, ou seja, no sentido a jusante. Embora a maior cobertura vegetal nesses pontos sugerisse temperaturas menores em relação aos demais sítios analisados, observou-se comportamento diverso do esperado.

De acordo com Siqueira (2019) [13], esse comportamento é reflexo da forte influência do efeito de barramento hidráulico que o rio Negro exerce sobre o Tarumã-Açu, especialmente sobre o baixo curso. O influxo superficial das águas do rio Negro na direção a montante do TarumãAçu alcança 17 km, e, em razão da troca térmica entre as águas mais aquecidas (e, portanto, menos densas) do Negro, estas tendem a se posicionar mais superficialmente; sendo mais alta a temperatura quanto mais próximo da foz [13].

Nos pontos alterados e na calha principal, a intensa movimentação de embarcações promove a circulação da água entre a região mais superficial (aquecida) e os estratos inferiores (mais frios), possivelmente minimizando os efeitos do rio Negro sobre a temperatura da água nesses pontos. Isso explicaria a menor amplitude e o menor valor médio de temperatura no CP2.

Tabela 2 - Estatística descritiva dos parâmetros físico-químicos de qualidade da água do baixo curso do rio Tarumã-Açu, no período de set./2019 a jul./2020.

\begin{tabular}{ccccccc}
\hline Parâmetros & $\overline{\boldsymbol{X}}$ & Md. & Min. & Máx. & SD & SE \\
\hline TA & 31,46 & 30,73 & 29,31 & 36,07 & 1,817063 & 0,247271 \\
\hline pH & 5,26 & 5,10 & 4,16 & 8,37 & 0,770899 & 0,104906 \\
\hline CE & 9,61 & 9,33 & 5,00 & 26,00 & 3,446471 & 0,469005 \\
\hline OD & 5,34 & 4,90 & 3,17 & 8,87 & 1,378252 & 0,187556 \\
\hline STD & 4,66 & 5,00 & 2,00 & 11,33 & 1,484709 & 0,202043 \\
\hline TB & 4,04 & 2,69 & 1,41 & 17,19 & 3,271744 & 0,445228 \\
\hline
\end{tabular}

TA: temperatura da água $\left({ }^{\circ} \mathrm{C}\right)$; CE: condutividade elétrica $(\mu \mathrm{S} / \mathrm{cm})$; OD: oxigênio dissolvido $(\mathrm{mg} / \mathrm{L})$; STD: sólidos totais dissolvidos (mg/L); TB: turbidez (NTU); $\bar{X}$ : média; Md.: mediana; SD: desvio padrão; SE: erro padrão.

No trecho analisado, o pH médio foi de 5,26 ( $\pm 0,770)$, variando de 4,16 no P2 (jul./2020) a 8,37 no A2 (nov./2019). Nas águas pretas, como as do rio Tarumã-Açu, o pH ácido, com valores abaixo de 6,0, está relacionado à presença de material orgânico (ácidos húmicos e fúlvicos) proveniente da decomposição da floresta [65, 66], constituindo condição natural.

Nos pontos médios CP2 e A2, onde foram observadas as maiores médias e variações no $\mathrm{pH}, \mathrm{o}$ despejo de efluentes a partir das edificações às margens, bem como, dos flutuantes e das embarcações que transitam nessa área, além do vazamento de óleo dos barcos e do posto de combustível podem ser os fatores responsáveis pela alcalinidade da água nos períodos de menor vazão [67], condição diversa daquela naturalmente observada nas águas pretas [66]. 
Nascimento e Silva (2010) [68], Pinto et al. (2009) [69], Santana e Barroncas (2007) [16] e Santos et al. (2006) [17], ao estudarem trechos da BHTA, também identificaram elevações no pH em pontos sob influência direta das áreas urbanizadas, nos períodos de menor vazão; especialmente no Igarapé da Bolívia, cuja confluência coincide com os pontos A2 e CP2. Estudos em diversas bacias observaram semelhante aumento do $\mathrm{pH}$ associado à baixa vazão e à maior antropização [42, 70, 71].
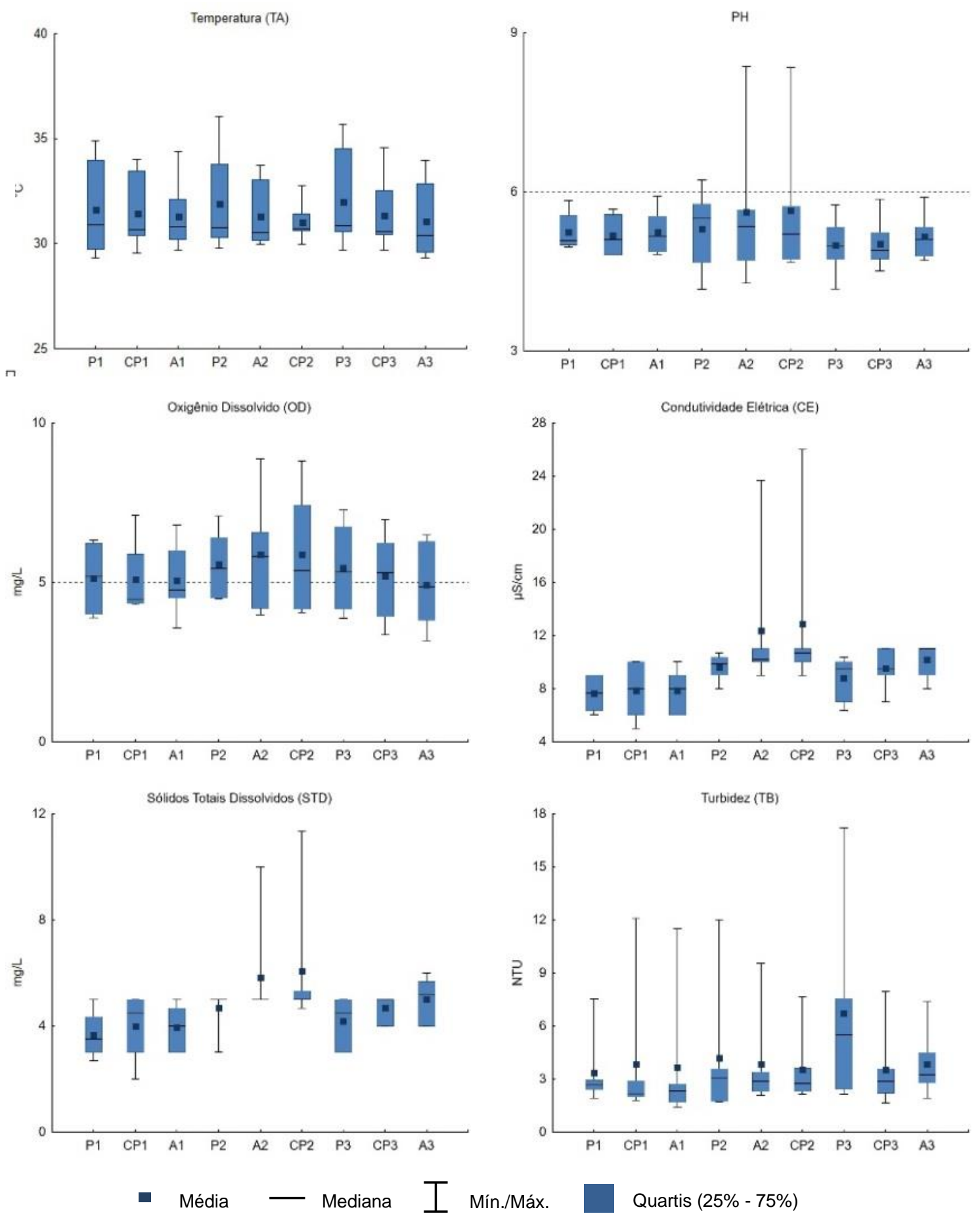

Figura 3 - Box Plot do sumário estatístico dos parâmetros físico-químicos de qualidade da água do baixo curso do rio Tarumã-Açu, no período de set./2019 a jul./2020. Para as variáveis pH e OD, a linha tracejada corresponde ao limite mínimo estabelecido na Resolução CONAMA no 357/2005, para águas de Classe 2. 
Foram identificados padrões semelhantes para os parâmetros STD e CE, cujos maiores valores médios também se referem aos pontos $\mathrm{CP} 2$ e A2, onde há uma intensa transformação antropogênica. Os estudos desenvolvidos por Bertossi et al. (2013) [72], Fernandes et al. (2011) [73], Gardiman Júnior e Simoura (2016) [74], Nagy et al. (2012) [42], Pereira et al. (2016) [71] e Silva et al. (2012) [75], acerca da influência das mudanças no uso da terra sobre a qualidade da água em bacias hidrográficas, igualmente constataram diferenças de STD e CE entre locais preservados e alterados, com valores maiores nas áreas perturbadas.

Para os STD, a erosão é um dos principais fatores de impacto sobre os recursos hídricos associados ao uso da terra [46]. Já o aumento da CE, além dos sedimentos erodidos e resíduos sólidos, pode refletir, ainda, a influência de efluentes domésticos [76]. No trecho analisado, a perda de cobertura florestal e a impermeabilização de superfícies, decorrentes da ocupação das margens, no ponto A2; o agravamento de processos erosivos, em ambas as margens, pelo trânsito intenso de embarcações, no CP2; e a produção e deposição irregular de resíduos sólidos, tanto pelas atividades antropogênicas em terra quanto embarcadas (flutuantes), elevam a concentração de STD nessa região. Somam-se a esses fatores a intensa contribuição de efluentes residenciais e resíduos sólidos ao longo das sub-bacias do Bolívia e do Gigante, que confluem para os pontos A2 e A3, respectivamente, com altos valores de CE.

Considerando o disposto no art. 42 da Resolução CONAMA n 357/2005, os resultados das análises de STD, TB, pH e OD foram comparadas com os valores referenciais de qualidade da água para a classe 2, estabelecidos no art. 15 da mesma norma [40], conforme Figura 3. Todos os pontos amostrados enquadram-se nos limites estabelecidos para os parâmetros STD e TB. Observa-se que, em relação ao $\mathrm{pH}$, embora os valores médios estejam abaixo do limite mínimo, os pontos $\mathrm{P} 2$, $\mathrm{CP} 2$ e A2 apresentaram registros dentro da faixa referenciada $(6,0 \leq \mathrm{pH} \geq 9,0)$ na legislação. Esses registros ocorreram em nov./2019 e divergem da condição natural das águas pretas $(\mathrm{pH}<6,0)$. Quanto ao OD, apenas o ponto A3 ficou, em média, abaixo do limite mínimo $(\mathrm{OD} \geq 5,0 \mathrm{mg} / \mathrm{L})$ para a classe 2 .

No período amostrado, o OD variou de $3,17 \mathrm{mg} / \mathrm{L}$ a $8,87 \mathrm{mg} / \mathrm{L}$, com valores mais altos mensurados em nov./2019. As baixas concentrações de OD observadas no rio Tarumã-Açu são consideradas naturais para rios amazônicos, segundo Silva et al. (2013) [65] e Silva et al. (2016) [77], em razão da depleção de oxigênio, pela degradação da matéria orgânica oriunda das áreas alagadas e da serapilheira, arrastada pelas chuvas para o leito dos corpos d'água.

A grande quantidade de matéria orgânica provoca o aumento da atividade microbiótica, na decomposição desses compostos, provocando a diminuição do oxigênio dissolvido. Baixas concentrações de OD, derivadas desse processo, também foram apontadas por Belém e Cabral (2019) [78], Miranda et al. (2009) [79], Pereira et al. (2016) [71], Pinto et al. (2009) [69]; Silva et al. (2013) [65] e Silva et al. (2016) [77], ao avaliarem outras bacias amazônicas. E, apesar de o OD ser importante para a salubridade do sistema, os organismos encontrados em águas pretas estão adaptados a esta condição [22, 78].

O OD é um fator limitante do processo de autodepuração em sistemas aquáticos naturais [22], e uma variável importante na avaliação da qualidade da água. Contudo, tratando-se de águas amazônicas, mesmo valores abaixo de $5,00 \mathrm{mg} / \mathrm{L}$ não indicam, por si só, a degradação da qualidade, por se tratar de condição natural $[65,69,77]$; já que o art. 38 , § $2^{\circ}$, da Resolução CONAMA $n^{\circ} 357 / 2005$ privilegia a condição natural em detrimento dos referenciais normativos das classes [40].

A turbidez variou de 1,41 NTU a 17,19 NTU, com maiores média e variância no P3. A ocorrência de processos erosivos e o menor volume da massa d'água podem estar relacionados ao aumento da turbidez nesse ponto, com consequente incremento da matéria em suspensão. A zona ciliar do P3 é composta, basicamente, por vegetação arbóreo-arbustiva, com as formações florestais ocorrendo em segundo plano. De acordo com Gardiman Junior e Simoura (2016) [74], a proporção e a posição das áreas de floresta influenciam a qualidade da água, pois a baixa densidade da vegetação deixa o solo suscetível ao surgimento de processos erosivos.

A localização do P3 (próximo à foz) o sujeita, com mais intensidade, aos efeitos do barramento hidráulico, já que, conforme Siqueira (2019) [13], a baixíssima velocidade média do rio TarumãAçu diminui fortemente em direção à jusante, fazendo com que os sedimentos vindos de montante se depositem nessa área. Esse argumento é reforçado por Nagy et al. (2012) [42], quando afirma 
que pequenas bacias na região do exutório tendem a apresentar baixo relevo e a acumular grandes quantidades de matéria orgânica e materiais particulados, com consequente aumento da turbidez e da concentração de STD.

No período de vazante, quando o volume de água e a influência do rio Negro diminuem, a TB e os demais parâmetros analisados registraram as maiores médias. Isso indica que a redução da cota diminui a capacidade de diluição do rio a jusante [46, 70]; e evidencia o papel do rio Negro na dinâmica de autodepuração das águas do canal principal da BHTA. Esses resultados são compatíveis com os estudos de Pinto et al. (2009) [69], Santana e Barroncas (2009) [16] e Santos et al. (2006) [17], que também observaram uma tendência de melhora da qualidade com o aumento do volume de água no Tarumã-Açu.

O teste de Shapiro-Wilk retornou, como esperado, distribuição incompatível com o padrão de distribuição normal $(\mathrm{p}<0,05)$, motivo pelo qual foram realizados testes estatísticos não paramétricos, incluindo a Correlação de Spearman. De acordo com Helsel e Hirsch (2002) [43], em geral, dados ambientais, em especial os relacionados aos recursos hídricos, apresentam distribuição não normal, com assimetria entre a média e a mediana.

A Tabela 3 mostra as correlações entre as variáveis analisadas. Na avaliação qualitativa, realizada com base nos critérios de Callegari-Jacques (2003) [80], as associações estatisticamente significativas são: muito forte entre CE/STD; forte entre $\mathrm{pH} / \mathrm{TB}$ e $\mathrm{pH} / \mathrm{TA}$; e moderadas para as demais.

Tabela 3 - Coeficientes de correlação de Spearman, obtidos como medida de associação entre as variáveis físico-químicas de qualidade da água do baixo curso do rio Tarumã-Açu, no período de set./2019 a jul./2020.

\begin{tabular}{ccccccc}
\hline & TA & pH & CE & OD & STD & TB \\
\hline TA & 1,000 & $\mathbf{0 , 8 2 0}$ & $-0,227$ & $\mathbf{0 , 3 8 7 ^ { * }}$ & $-0,296$ & $\mathbf{0 , 5 7 7 ^ { * }}$ \\
pH & & 1,000 & $-0,121$ & $\mathbf{0 , 5 3 8}^{*}$ & $-0,160$ & $\mathbf{0 , 6 5 0}$ \\
CE & & 1,000 & $-0,332$ & $\mathbf{0 , 9 0 1 *}$ & $-0,119$ \\
OD & & & 1,000 & $-0,322$ & $\mathbf{0 , 4 2 0 *}$ \\
STD & & & & 1,000 & $-0,185$ \\
TB & & & & & 1,000 \\
\hline
\end{tabular}

*Correlação estatisticamente significativa $(\mathrm{p} \leq 0,01)$. TA: temperatura da água; CE: condutividade elétrica; OD: oxigênio dissolvido; STD: sólidos totais dissolvidos; TB: turbidez.

Com base no que já foi discutido e considerando que, segundo Figur e Reis (2017) [22], Hwang et al. (2016) [3] e Silva et al. (2012) [75], os parâmetros físico-químicos de qualidade da água podem ser bastante influenciados por características ambientais, calculou-se a correlação entre as variáveis físico-químicas e a cota do rio Negro nos dias de medição e a pluviosidade acumulada nas 24 horas anteriores à data das análises (Tabela 4).

Tabela 4 - Correlação de Spearman entre os parâmetros físico-químicos de qualidade da água e a cota do Rio Negro; e a pluviosidade acumulada nas 24 horas anteriores às análises.

\begin{tabular}{cccccccc}
\hline \multicolumn{2}{c}{ Cota/Pluviosidade } & TA & pH & CE & OD & STD & TB \\
\hline \multirow{2}{*}{ Cota } & R Spearman & $-0,771$ & $\mathbf{- 0 , 8 2 8 *}$ & $-0,028$ & $\mathbf{- 0 , 9 4 2 *}$ & 0,771 & $-0,771$ \\
\cline { 2 - 8 } & p-value & 0,072 & 0,041 & 0,957 & 0,004 & 0,072 & 0,072 \\
\hline \multirow{2}{*}{$\begin{array}{c}\text { Pluviosidade } \\
\text { (24h) }\end{array}$} & R Spearman & $-0,579$ & $-0,637$ & $-0,318$ & $-0,028$ & $-0,318$ & $\mathbf{- 0 , 8 1 1 *}$ \\
\cline { 2 - 8 } & p-value & 0,227 & 0,173 & 0,537 & 0,956 & 0,537 & 0,049 \\
\hline
\end{tabular}

* Correlação estatisticamente significativa ( $\mathrm{p} \leq 0,05)$. TA: temperatura da água; CE: condutividade elétrica; OD: oxigênio dissolvido; STD: sólidos totais dissolvidos; TB: turbidez.

Faz-se necessário esclarecer que a utilização da cota do rio Negro, como referência para os cálculos de correlação, deu-se em razão da ausência de dados de monitoramento do nível do Tarumã-Açu; e da influência do primeiro sobre o último, em função do processo de barramento hidráulico. Como demonstrado por Siqueira (2019) [13], quando o rio Negro atinge 19 m, ele e o 
Tarumã-Açu entram em fase, ou seja, ocorre sincronização do nível da água. As cotas nas datas das análises foram $\geq 18,87 \mathrm{~m}$, o que dá suporte à correlação.

Como foi colocado anteriormente, o processo de decomposição da matéria orgânica derivada do chão florestal leva ao consumo e depleção do $\mathrm{OD}$, e libera ácidos húmicos e fúlvicos, que reduzem o pH nos rios de águas pretas. Logo, a correlação entre pH e OD já era esperada; bem como, entre OD e TA, uma vez que a elevação da temperatura reduz a solubilidade ao oxigênio na interface ar-água [41].

Considerando que o aumento de $\mathrm{pH}$ e TB em bacias urbanas e periurbanas está, geralmente, associado ao lançamento de efluentes domésticos [37, 38, 71], a correlação entre essas variáveis reflete o impacto da ocupação urbana sem ordenamento sobre a qualidade da água, nos pontos alterados. No entanto, diferente de Araújo et al. (2018) [41], Nagy et al. (2012) [42] e Souza e Gastaldini (2014) [76], o teste de Spearman não constatou correlação significativa entre TB e STD (Tabela 4). A concentração de STD influencia diretamente os valores de CE, conforme Santos e Hernandez (2013) [81].

A elevação do nível da água, além de aumentar o potencial de diluição, resulta em grandes áreas alagadas, onde a vegetação fica parcial ou completamente submersa, acrescendo a quantidade de matéria orgânica disponível à ação dos micro-organismos decompositores $[65,77]$. Isso justifica a correlação negativamente significativa entre a cota e as variáveis pH e OD (Tabela 7). Esse tipo de correlação foi igualmente reportado por Souza e Gastaldini (2014) [76]. Nenhum outro parâmetro mostrou correlação significativa com a cota.

Quanto à pluviosidade, apenas TB apresentou correlação significativa (negativa), conforme Tabela 4, o que pode estar associado à diluição de despejos devido às chuvas [41]. Menezes et al. (2016) [37] e Santos e Hernandez (2013) [81] observaram semelhante relação entre TB e a ocorrência de chuvas, em bacias sem ordenamento do uso da terra e com alta densidade residencial e de estradas. A ausência de correlação entre a pluviosidade e STD e CE, reforça a sugestão de diferença das principais fontes poluidoras entre esses fatores e a turbidez. Os primeiros sendo mobilizados de fontes terrestres, principalmente processos erosivos, e o último do lançamento de efluentes [42].

As análises multivariadas foram empregadas para checar se havia diferença na qualidade da água entre os pontos preservados e alterados e identificar as variáveis que direcionaram os resultados e suas relações. A análise hierárquica de Cluster (hierarchical Cluster analysis - HCA) gerou três agrupamentos distintos (Figura 4): Grupo 1, formado pelos pontos CP2 e A2 na segunda amostragem; Grupo 2, composto pelos demais pontos também na segunda amostragem; e o Grupo 3, referente às demais avaliações.

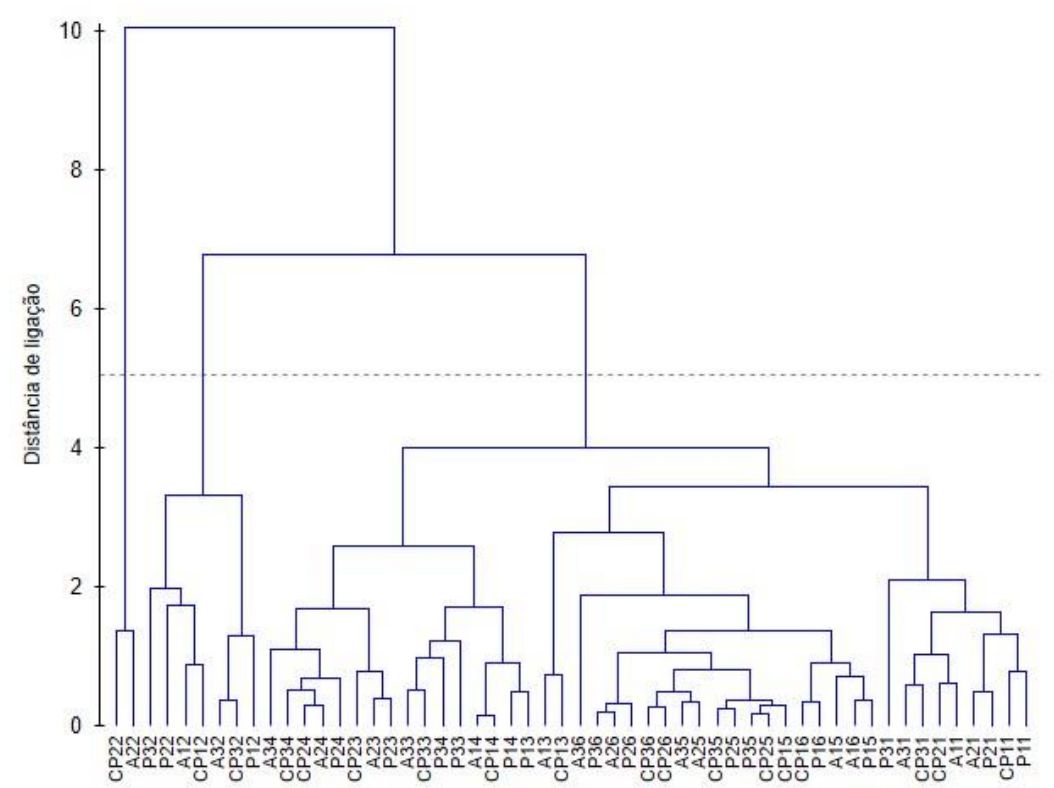

Figura 4 - Dendrograma de agrupamento dos pontos amostrados no período de estudo (set./2019 a jul./2020), na bacia do Tarumã-Açu. 
A segunda amostragem foi realizada em nov./2019, quando foi registrado o menor nível de água dentre os meses amostrados. A distinção dos pontos CP2 e A2 (Grupo 1), em relação aos demais pontos (Grupo 2), deu-se em função dos altos valores de STD e CE. Os demais pontos amostrados, nessa mesma data, registraram valores médios altos para TA, $\mathrm{pH}, \mathrm{OD}$ e TB, apenas. Esse resultado supõe o aporte de grande quantidade de material particulado, oriunda de processos erosivos e/ou descarte irregular de resíduos sólidos, seja nas imediações dos pontos de amostragem ou drenados a montante pelo igarapé da Bolívia e seus afluentes.

Conforme mapeamento do uso e ocupação da terra, bem como salientado nos estudos de Braga et al. (2012) [14], Pinto et al. (2009) [69], Santana e Barroncas (2007) [16], Santos et al. (2006) [17] e Siqueira (2019) [13], o igarapé da Bolívia drena uma área bastante antropizada e fragmentada, com atividade ilegal de extração de areia e outros minerais, e tributários já assoreados ou em processo.

Com relação ao Grupo 3, nota-se certo padrão na distribuição dos subgrupos, de acordo com o mês/cota (jan. e mar./20, mai. e jul./20 e set./19) e com o estado de conservação, havendo uma pré-disposição de agrupamento entre os pontos alterados (A) e do canal principal $(\mathrm{CP})$ mais a jusante, onde os impactos antropogênicos são mais intensos.

A análise de componentes principais (principal component analysis - PCA) mostrou, de forma sintética, a forte relação entre a qualidade e o volume da água no baixo curso da BHTA, e o seu potencial de autodepuração. Fica evidente, ainda, a relação entre a perda de cobertura florestal e do grau de antropização sobre a qualidade hídrica, quando há diminuição da vazão, como ocorre nos pontos A2 e A3, que correspondem ao exutório dos igarapés da Bolívia e do Gigante, respectivamente, cuja rede fluvial drena áreas densamente urbanizadas e com intenso lançamento de resíduos sólidos e efluentes domésticos [14, 16, 17].

Apenas duas componentes agrupam $84,21 \%$ dos dados originais. A primeira componente (Fator 1) explica 50,65\% e a segunda componente (Fator 2) 33,56\% da variabilidade dos dados. De acordo com Jolliffe (2002) [82], uma variância total acumulada entre 70\% e 90\% representa de forma satisfatória a variância original. Conforme Figura 5, o Fator 1 modela, principalmente, as variações de $\mathrm{pH}$ e OD, enquanto o Fator 2 é direcionado pelos parâmetros STD e CE.

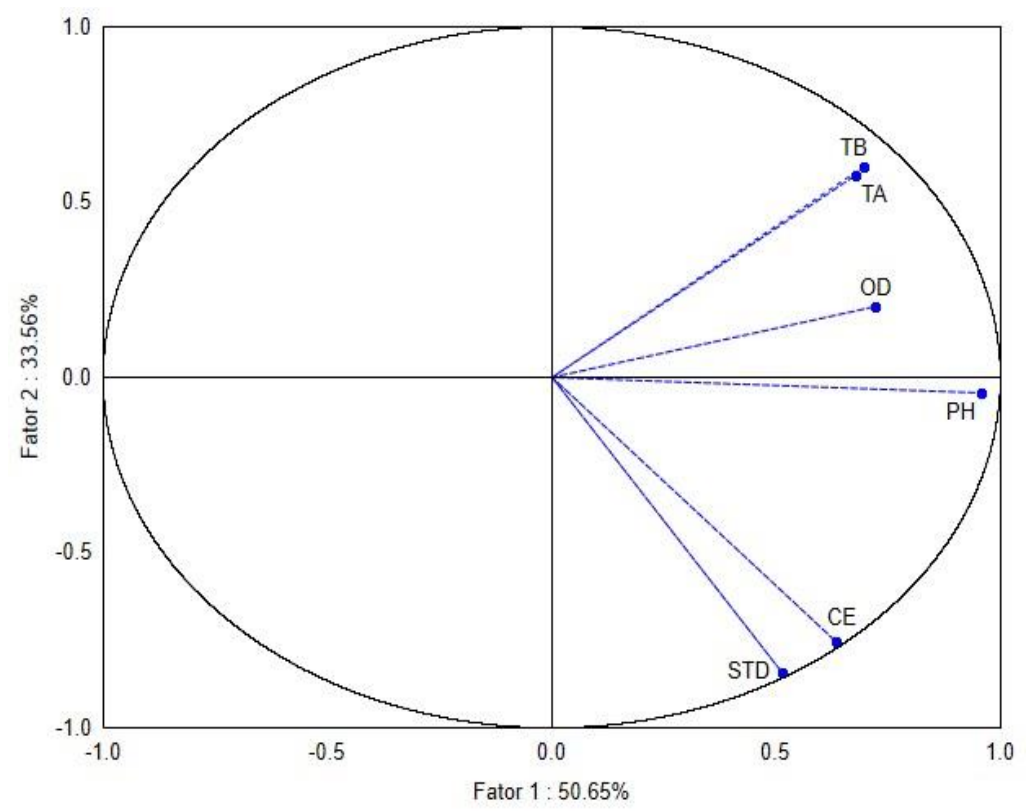

Figura 5 - Análise de componente principal (PCA) dos parâmetros de qualidade da água. Projeção das variáveis sobre o fator ( $1 \times 2$ ).

Ratificando as análises anteriores, o Fator 1 corresponde à cota dos canais fluviais no baixo curso da BHTA, o que é condizente com os dados de medição, que registraram maiores médias de $\mathrm{pH}$ e OD em nov./2020, quando o nível da água nos pontos amostrados era menor. O Fator 2 
é o que apresenta maior correlação com o estado de transformação antrópica (preservado ou alterado), ou seja, com a perda da cobertura florestal natural, cujas variações de STD e CE foram maiores nos pontos A2, CP2, A3 e CP3. A projeção dos resultados da PCA para os pontos amostrados está exposta na Figura 6.

Diversos estudos constataram semelhantes variações de PH/OD e STD/CE ligados ao fluxo e à cobertura florestal das bacias hidrográficas, respectivamente [22, 37, 38, 41, 42, 75]. De forma análoga com esses autores, o presente estudo não verificou direta associação entre a qualidade da água e o estado de conservação dos pontos amostrados no baixo curso da BHTA.

Segundo asseveram Hwang et al. (2016) [3], a qualidade da água nem sempre estabelece uma relação linear com a proporção de usos antropogênicos da terra, sobretudo em sistemas mais complexos, nos quais deve haver mais fatores de ruptura dessa relação, como fatores geoambientais. Para Silva et al. (2012) [75], fatores como OD, por exemplo, refletem mais alterações ambientais do que no uso da terra. Dessa forma, a simples preservação de fragmentos de vegetação ripária não é suficiente para garantir a qualidade eco-hidrológica de uma bacia, sendo necessária adoção de medidas de gerenciamento que considerem a dinâmica em toda a área de captação [12].

Essas medidas devem incluir a gestão dos recursos hídricos subterrâneos, tendo em vista que a redução e a alteração na distribuição das áreas florestadas, causadas pela fragmentação da paisagem, afetam as propriedades hidráulicas do solo e as condicionantes da recarga difusa da bacia, podendo levar a perdas na quantidade e qualidade das águas sub-superficiais, especialmente em bacias urbanas e periurbanas [83-85].

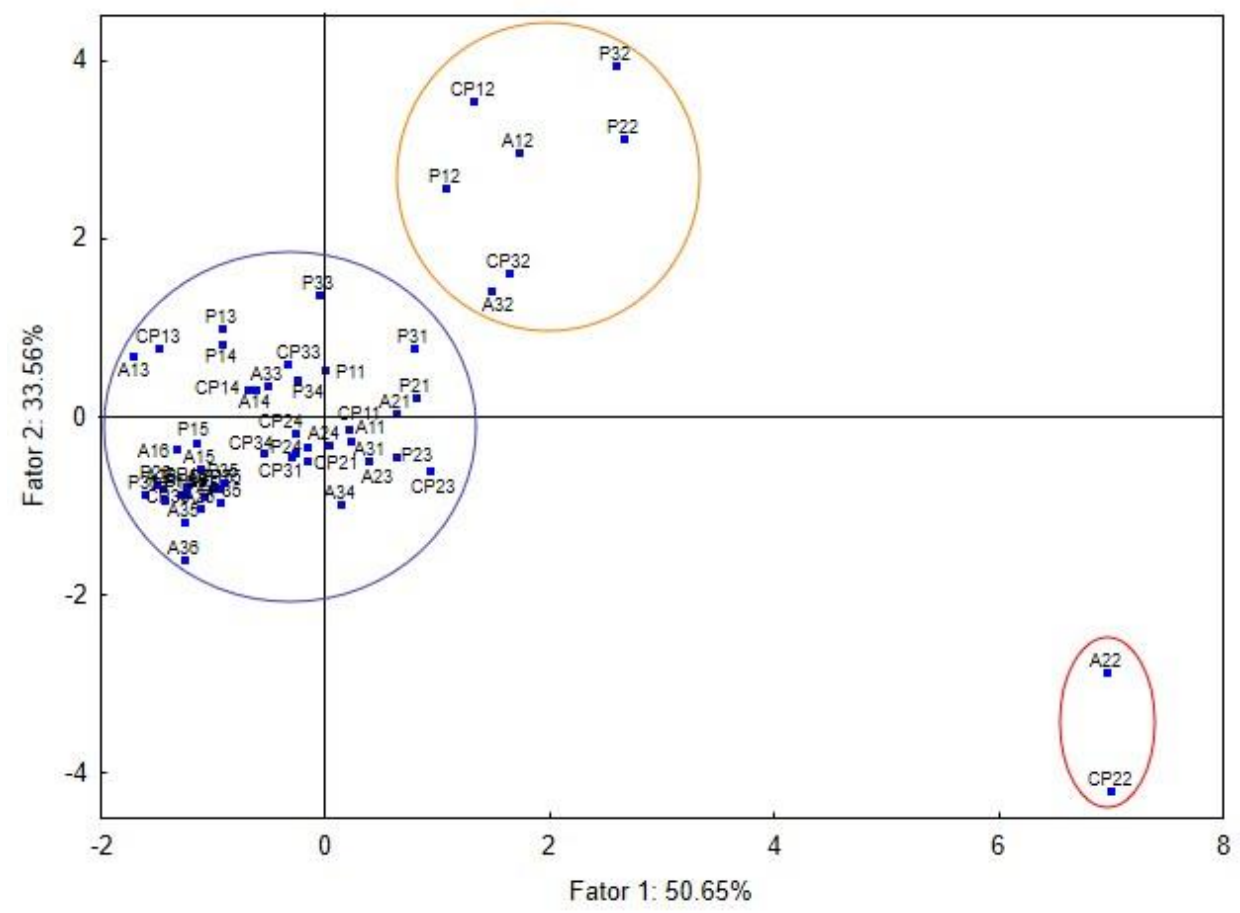

Figura 6 - Biplot da PCA, com a projeção dos pontos amostrados, nos diferentes meses de análise, de acordo com os parâmetros de qualidade da água, evidenciando a formação de três grupos distintos.

Assim, o desafio chave dos gestores é compreender, de forma holística, a dinâmica ecohidrológica da bacia e integrá-la às políticas e planos, de modo a equilibrar as dimensões ecossistêmica e socioeconômica, na definição de metas coletivas de gestão [84]. Contudo, essa gestão integrada entre água e terra requer não apenas uma base científica sólida, mas também a compreensão, o compromisso e a colaboração dos diferentes atores, garantindo que todos os aspectos socioeconômicos e ambientais para o desenvolvimento da bacia sejam considerados e representados [10]. 
Alterações em um ou outro parâmetro podem não impactar negativamente uma atividade específica. Contudo, a BHTA apresenta uma multiplicidade de usos, incluindo aqueles que exigem um padrão de qualidade de água mais elevado, como consumo humano (principalmente a partir de fontes subterrâneas) e recreação de contato primário. E, conforme estabelecem o art. $9^{\circ}$, inciso I, da Lei $n^{\circ} 9.433 / 97$, e o art. $38^{\circ}$, $\S 1^{\circ}$, da Resolução CONAMA no $357 / 2005$, a qualidade da água deve ser compatível com os usos mais restritivos [11,40].

\section{CONCLUSÃo}

O mapeamento e classificação do uso e cobertura da terra mostram a supressão das áreas florestadas, em razão da expansão desordenada do processo de urbanização e para o desenvolvimento de atividades produtivas (turismo, agropecuária, extrativismo e mineração), e a formação de unidades de paisagem antropizadas.

Na margem esquerda do baixo curso, o uso da terra foi consolidado para fins urbanos, contudo, ainda são necessárias ações de controle do desmatamento e de proteção das manchas de floresta remanescentes. Tendo o rio Tarumã-Açu como limitador a oeste, a degradação da paisagem natural da bacia tem se intensificado em direção à cabeceira. $\mathrm{O}$ médio curso já apresenta ITA regular, tal qual o baixo curso. $\mathrm{O}$ alto curso, apesar de ainda classificado como pouco degradado, registra perda de vegetação associada à construção da BR-174 e à abertura de ramais e vicinais.

Quanto à qualidade da água, com exceção do $\mathrm{pH}$, todos os demais parâmetros analisados estão, em média, de acordo com os padrões do CONAMA para águas de Classe 2. O pH ácido, contudo, constitui condição natural para águas pretas. Constatou-se, ainda, que a perda de cobertura florestal e os usos antropogênicos contribuíram para o aumento nos valores de $\mathrm{pH}, \mathrm{OD}, \mathrm{CE}, \mathrm{STD}$ e TB nos pontos alterados, sob influência dos igarapés da Bolívia e do Gigante, especialmente nos períodos de vazante e de menor pluviosidade.

\section{AGRADECIMENTOS}

Agradecemos à Coordenação de Aperfeiçoamento de Pessoal de Nível Superior (CAPES) Código de Financiamento 001, à Agência Nacional de Águas (ANA) e ao Programa de Mestrado Profissional em Rede Nacional em Gestão e Regulação de Recursos Hídricos (PROFÁGUA), Projeto CAPES/ANA AUPEX nº 2.717/2015, pelo apoio técnico-científico.

\section{REFERÊNCIAS BIBLIOGRÁFICAS}

1. Creed IF, Weber M, Accatino F, Kreutzweiser DP. Managing forests for water in the Anthropocene the best kept secret services of forest ecosystems. Forests. 2016;7(60):1-23. doi: 10.3390/f7030060

2. Wright JS, Fu R, Worden JR, Chakraborty S, Clinton NE, Risi C, et al. Rainforest-initiated wet season onset over the southern Amazon. Proc Natl Acad Sci USA. 2017;114(32):8481-6. doi: 10.1073/pnas.1621516114

3. Hwang SA, Hwang SJ, Park SR, Lee SW. Examining the relationships between watershed urban land use and stream water quality using linear and generalized additive models. Water. 2016;8(155):1-15. doi: 10.3390/w8040155

4. Brogna D, Michez A, Jacobs S, Dufrêne M, Vincke C, Dendoncker N. Linking forest cover to water quality: a multivariate analysis of large monitoring datasets. Water. 2017;9(176):1-17. doi: 10.3390/w9030176

5. Sheil D. Forests, atmospheric water and an uncertain future: the new biology of the global water cycle. Forest Ecosyst. 2018;5(19):1-22. doi: 10.1186/s40663-018-0138-y

6. Viglizzo E, Jobbágy E, Ricard M, Paruelo J. Partition of some key regulating services in terrestrial ecosystems: meta-analysis and review. Sci Total Environ. 2016 Aug;562:47-60. doi: 10.1016/j.scitotenv.2016.03.201

7. Wang-Erlandsson L, Fetzer I, Keys PW, Van Der Ent RJ, Savenije HHG, Gordon LJ. Remote land use impacts on river flows through atmospheric teleconnections. Hydrol Earth Syst Sci. 2018;22(8):431128. doi: 10.5194/hess-22-4311-2018 
8. Lawrence D, Vandecar K. Effects of tropical deforestation on climate and agriculture. Nature Clim Change. 2015;5:27-36. doi: 10.1038/nclimate2430

9. Mekonnen MM, Hoekstra AY. Four billion people facing severe water scarcity. Science Advances. 2016 Feb;2(2):1-6. doi: 10.1126/sciadv.1500323

10. Ellison D, Morris CE, Locatelli B, Sheil D, Cohen J, Murdiyarso D, et al. Trees, forests and water: cool insights for a hot world. Global Environm Change. 2017;43:51-61. doi: 10.1016/j.gloenvcha.2017.01.002

11. Brasil. Lei $\mathrm{n}^{\circ}$ 9.433, de 08 de janeiro de 1997. Institui a Política Nacional de Recursos Hídricos, cria o Sistema Nacional de Gerenciamento de Recursos Hídricos, regulamenta o inciso XIX do art. 21 da Constituição Federal, e altera o art. $1^{\circ}$ da Lei $n^{\circ} 8.001$, de 13 de março de 1990, que modificou a Lei ${ }^{\circ}$ 7.990, de 28 de dezembro de 1989. Diário Oficial da União. 09 jan 1997;6(Seção 1):470-4. Disponível em: http://www.planalto.gov.br/ccivil_03/leis/19433.htm

12. Brogna D, Dufrêne M, Michez A, Latli A, Jacobs S, Vincke C, et al. Forest cover correlates with good biological water quality. Insights from a regional study (Wallonia, Belgium). J Environm Managem. 2018;211:9-21. doi: 10.1016/j.jenvman.2018.01.017

13. Siqueira LF. Estudo hidrológico do efeito de barramento hidráulico no rio Tarumã-Açu, Manaus-AM [dissertação]. Manaus (AM): Instituto Nacional de Pesquisas da Amazônia; Universidade do Estado do Amazonas; 2019. 65 p.

14. Braga KAAF, Silva FF, Schaffrath VR. Microbacia do Igarapé do Gigante: unidade de planejamento para a bacia do Tarumã. Rev Agroneg Meio Amb. 2012 Jan/Apr;5(1):103-29.

15. Vasconcelos MA. Estudo da paisagem do setor sul da Bacia Hidrográfica do Tarumã-Açu, Manaus, utilizando imagens multipolarizadas do radar Alos/Palsar [dissertação]. Manaus (AM): Universidade Federal do Amazonas; 2012. 75 p.

16. Santana GP, Barroncas PSR. Estudo de metais pesados (Co, $\mathrm{Cu}, \mathrm{Fe}, \mathrm{Cr}, \mathrm{Ni}, \mathrm{Mn}, \mathrm{Pb}$ e $\mathrm{Zn}$ ) na Bacia do Tarumã-Açu Manaus - (AM). Acta Amaz. 2007;37(1):111-8. doi: 10.1590/S0044-59672007000100013

17. Santos IN, Horbe AMC, Silva MSR, Miranda SAF. Infulência de um aterro sanitário e de efluentes domésticos nas águas superficiais do Rio Tarumã e afluentes - AM. Acta Amaz. 2006;36(2):229-36. doi: 10.1590/S0044-59672006000200013

18. Costa EBS, Silva CL, Silva ML. Caracterização física de bacias hidrográficas na região de Manaus AM. Caminhos Geogr. 2013 Jun;14(46):93-100.

19. Costa JR, Soares JEC, Mota AM, Coral ST. Ações integradas em busca da sustentabilidade no Assentamento Tarumã-Mirim, zona rural de Manaus (AM). Rev Bras Agroecol. 2012;7(1):14-24.

20. Empresa Brasileira de Pesquisa Agropecuária (EMBRAPA). Diagnóstico sócio-ambiental do Projeto de Assentamento Tarumã Mirim. Manaus: INCRA/SEPROR; 2003.

21. Antonio IC. Índices climáticos e caracterização climática no entorno de Manaus. Rev Bras Geogr Fís. 2017;10(4):1120-33. doi: 10.26848/rbgf.v10.4.p1120-1133

22. Figur C, Reis JT. A influência do uso e cobertura da terra nos parâmetros de qualidade da água na bacia hidrográfica do rio Abaúna, em Getúlio Vargas, RS. Ciência e Natura. 2017 May/Aug;39(2):352-65. doi: $10.5902 / 2179460 X 24335$

23. Ribeiro HV, Galvanin EAS, Paiva MM. Análise das pressões antrópicas na bacia Paraguai/Jauquara Mato Grosso. Ciência e Natura. 2017 May/Aug;39(2):378-89. doi: 10.5902/2179460X26090

24. Abreu KMP, Coutinho LM. Sensoriamento remoto aplicado ao estudo da vegetação com ênfase em índice de vegetação e métricas de paisagem. Vértices. 2014 Jan/Apr;16(1):173-98. doi: 10.5935/18092667.20140012

25. Instituto Brasileiro de Geografia e Estatística (IBGE). Manual técnico de uso da terra. 3. ed. Rio de Janeiro: IBGE; 2013.

26. Guglielmeli ACO, Silva SML, Strauch JCM. Análise multitemporal do grau de antropização da Área de Proteção Ambiental Municipal do Rio Uberaba, Uberaba, MG. RBCIAMB. 2018 Jun;48:114-27. doi: $10.5327 / Z 2176-947820180331$

27. Rusca GG, Moraes MCP, Valente RA, Piña-Rodrigues FCM. Análise espacial dos fragmentos florestais no entrono de uma Unidade de Conservação de Proteção Integral. RBCIAMB 2017 Jun;44:85-94. doi: $10.5327 / Z 2176-947820170146$

28. Landis JR, Koch GG. The measurement of observer agreement for categorical data. Biometrics. 1977 Mar;33(1):159-74. doi: 10.2307/2529310

29. Jesus EN, Ferreira RA, Aragão AG, Santos TIS, Rocha SL. Estrutura dos fragmentos florestais da Bacia Hidrográfica do Rio Poxim - SE, como subsídio à restauração ecológica. Rev Árvore. 2015;39(3):46774. doi: 10.1590/0100-67622015000300007

30. Lémechev T. On hydrological heterogeneity catchment morphology and catchment response. J Hydrol. $1982 ; 100(1-3): 357-75$. 
31. Almeida AS, Vieira ICG. Transformações antrópicas da paisagem agrícola com palma de óleo no Pará. Novos Cadernos NAEA. 2019 May/Aug;22(2):9-26. doi: 10.5801/ncn.v22i2.6535

32. Cocco J, Ribeiro HV, Galvanin EAS. Intensity of anthropic action in the Diamantino River sub-basin, Mato Grosso State/Brazil. Geografia. 2015 Aug;40(especial):71-84.

33. Miranda MRS, Neves SMAS, Ramos AWP. Caracterização das unidades de paisagem da bacia hidrográfica do rio Jauru - Mato Grosso, Brasil. Cad Geogr. 2019;29(28):765-85. doi: 10.5752/p.23182962.2019v29n58p765

34. Pereira FS, Vieira ICG. Transformação antrópica na bacia hidrográfica do rio Gurupi, Amazônia oriental. Sustainability in Debate. 2019 Dec;10(3):224-35. doi: 10.18472/SustDeb.v10n3.2019.23799

35. Perim MA, Cocco MD. A. Efeito das transformações antrópicas às margens do rio Uma, Taubaté, São Paulo, Brasil. Rev Ambient Água. 2016;11(suplementar):1163-71. doi: 10.4136/1980-993X

36. Cruz CBM, Teixeira AJA, Barros RS, Argento MSF, Mayr LM, Menezes PML. Carga antrópica da bacia hidrográfica da Baía de Guanabara. In: Anais do IX Simpósio Brasileiro de Sensoriamento Remoto; 11-18 set 1998. Santos (SP): INPE; 1998. p. 99-109.

37. Menezes JPC, Bittencourt RP, Farias MS, Bello IP, Fia R, Oliveira LFC. Relação entre padrões de uso e ocupação do solo e qualidade da água em uma bacia hidrográfica urbana. Eng Sanit Ambiental. 2016 Jul/Sep;21(3):519-34. doi: 10.1590/S1413-41522016145405

38. Santos JP, Martins I, Callisto M, Macedo DR. Relações entre qualidade da água e uso e cobertura do solo em múltiplas escalas espaciais na bacia do Rio Pandeiros, Minas Gerais. Rev Espinhaço. 2017;6(2):36-46. doi: 10.5281/zenodo.2575760.svg

39. Companhia Ambiental do Estado de São Paulo (CETESB); Agência Nacional de Águas (ANA). Guia nacional de coleta e preservação de amostras: água, sedimento, comunidades aquáticas e efluentes líquidos. São Paulo (SP): CETESB, Brasília (DF): ANA; 2011.

40. Brasil. Ministério do Meio Ambiente, Conselho Nacional do Meio Ambiente. Resolução no 357, de 18 de março de 2005. Dispõe sobre a classificação dos corpos de água e diretrizes ambientais para o seu enquadramento, bem como estabelece as condições e padrões de lançamento de efluentes, e dá outras providências. Diário Oficial da União. 18 mar 2005;53(Seção 1):58-63. Disponível em: http://www.siam.mg.gov.br/sla/download.pdf?idNorma $=2747$

41. Araujo PL, Hamburger DS, Jesus TA, Benassi RF, Cicco V. Relação entre a qualidade da água e o uso do solo em microbacias do reservatório Billings, na Região Metropolitana de São Paulo - SP. REGA. 2018;15(e2):[19 p.]. doi: 10.21168/rega.v15e2

42. Nagy RC, Lockaby BG, Kalin L, Anderson C. Effects of urbanization on stream hydrology and water quality: the Florida Gulf Coast. Hydrol Process. 2012;26(13):2019-30. doi: 10.1002/hyp.8336

43. Helsel DR, Hirsch RM. Statistical methods in water resources. Reston (VA): U. S. Geological Survey; 2002. doi: 10.3133/twri04A3

44. Carvalho DP, Molinari DC. Caracterização das voçorocas na BR-174: trecho Manaus - Presidente Figueiredo (Amazonas). Rev Geogr Acadêm. 2014;8(2):5-19. doi: 10.18227/1678-7226rga.v8i2.2971

45. Erdogan BU. Regulation and mitigation services of forests as the components of urban resilience. European Water. 2017;59:395-401.

46. Pérez DJO, Carvalho SL. Aplicação de dois indicadores ambientais para quantificação da antropização da Microbacia do Córrego do Ipê (SP) - Brasil. Rev Ciências Agrí́c. 2012;29(2):93-107.

47. Instituto Nacional de Pesquisas Espaciais (INPE). TerraBrasilis - PRODES (Desmatamento) [Internet]. Brasília (DF): INPE; 2019 [acessado em 20 dez 2019]. Disponível em: http://terrabrasilis.dpi.inpe.br/app/map/deforestation?hl=pt-br

48. Farinaci JS, Batistella M. Variação na cobertura vegetal nativa em São Paulo: um panorama do conhecimento atual. Rev Árvore. 2012;36(4):695-705. doi: 10.1590/S0100-67622012000400011

49. Almeida CA, Valeriano DM, Escada MIS, Rennó CD. Estimativa de área de vegetação secundária na Amazônia Legal brasileira. Acta Amazonica. 2010;40(2):289-302. doi: 10.1590/S004459672010000200007

50. Gouveia RGL, Galvanin EAS, Neves SMAS. Aplicação do Índice de Transformação Antrópica na análise multitemporal da Bacia do Córrego do Bezerro Vermelho em Tangará da Serra-MT. Rev Árvore. 2013;37(6):1045-54. doi: 10.1590/S0100-67622013000600006

51. Rodrigues LC, Neves SMAS, Neves RJ, Galvanin EAS, Silva JSV. Avaliação do grau de transformação antrópica da paisagem da bacia do rio Queima-Pé, Mato Grosso, Brasil. RBCIAMB. 2014 Jun;32:5264.

52. Lees AC, Moura NG, Almeida AS, Vieira ICG. Poor prospects for avian biodiversity in Amazonian oil palm. Plos One 2015;10(5):e0122432. doi: 10.1371/journal.pone.0122432

53. Brasil. Ministério do Meio Ambiente. Cadastro Nacional de Unidades de Conservação (CNUC) [Internet]. Brasília (DF): MMA; 2020 [acesso em 29 jul 2020]. Disponível em: https://antigo.mma.gov.br/areas-protegidas/cadastro-nacional-de-ucs.html 
54. Barlow J, Lennox GD, Gardner TA. Anthropogenic disturbance in tropical forests can double biodiversity loss from deforestation. Nature. 2016 July;535:144-47. doi: 10.1038/nature18326

55. Brown CJ, Bode M, Venter O, Barnes MD, McGowan J, Runge CA, et al. Effective conservation requires clear objectives and prioritizing actions, not places or species. Proc Natl Acad Sci. 2015 Aug;112(32):e4342. doi: 10.1073/pnas.1509189112

56. Paiva PFPR, Ruivo MLP, Silva Júnior OMS, Maciel MNM, Braga TGM, Andrade MMN, et al. Deforestation in protect areas in the Amazon: a threat to biodiversity. Biod Conserv. 2019;29:[20 p.]. doi: 10.1007/s10531-019-01867-9

57. Da Silva RS, Barbosa CO, Monteiro FG, Correa DL, Gomes AS. Análise multitemporal de parte da Reserva do Alto Rio Guamá, Paragominas, PA. Pesquisa Florestal Brasileira 2019;39(1):1-10. doi: 10.4336/2019.pfb.39e201801712

58. Oliveira FM, Nunes TS. Aplicação de protocolo de avaliação rápida para caracterização da qualidade ambiental do manancial de captação (Rio Pequeno) do município de Linhares, ES. Natureza. 2015;13(2):86-91.

59. Silva TGN, Gama RC, Teixeira LG, Santos GR, Sousa RM, Souza PB. Diagnóstico ambiental de uma Área de Proteção Permanente (APP), Formoso do Araguaia - TO. Rev Univ Vale Rio Verde. 2018;16(2):1-10. doi: 10.5892/ruvrd.v16i2.4619

60. Rodriguez JMM, Silva EV, Cavalcanti APB. Geoecologia das paisagens: uma visão geossistêmica da análise ambiental. 5. ed. Fortaleza (CE): Edições UFC; 2017.

61. Carvalho JAL, Cunha SB. Terras caídas e consequências sociais na Costa do Miracauera, município de Itacoatiara - Amazonas, Brasil. Rev Geogr Am Cent. 2011;2(47E):1-16.

62. Labadessa AS. "Terras caídas", as causas e implicações socioeconômicas: uma análise preliminar na comunidade de Calama - baixo rio Madeira/RO. Bol Paranaense Geoci. 2014;71(1):12-20. doi: 10.5380/geo.v71i0.24930

63. Marques RO, Carvalho JAL. Processos fluviais no Rio Amazonas: erosão lateral e implicações para a cidade de Parintins. Rev Geonorte. 2019;10(35):108-32. doi: 10.21170/geonorte.2019.V.10.N.35.108.132

64. Queiroz MS, Tomaz Neto AG. A influência dos rios Negro e Solimões nas comunidades rurais ribeirinhas no município de Iranduba - Amazonas. In: Pinheiro LS, Gorayeb A, organizadores. Geografia física e as mudanças globais [Livro digital]. Fortaleza (CE): Editora UFC; 2019 [acesso em 12 ago 2020]. p. 1-12. Disponível em: http://www.editora.ufc.br/images/imagens/pdf/geografia-fisicae-as-mudancas-globais/441.pdf.

65. Silva MSR, Miranda SAF, Domingos RN, Silva SLR, Santana GP. Classificação dos rios da Amazônia: uma estratégia para preservação desses recursos. Holos Environment. 2013;13(2):163-74. doi: 10.14295/holos.v13i2.7344

66. Sioli H, Klinge H. Solos, tipos de vegetação e águas na Amazônia. Bol Museu Paraense Emílio Goeldi. $1962 ; 1: 1-18$

67. Von Sperling M. Introdução à qualidade das águas e ao tratamento de esgotos. 3. ed. Belo Horizonte (MG): UFMG; 2005.

68. Nascimento CR, Silva MRS. Alterações em parâmetros físicos e em concentrações de cátions e ânions em uma microbacia hidrográfica de Manaus devido à expansão urbana. Caminhos Geografia. 2010 Mar;11(33):208-19.

69. Pinto AGN, Horbe AMC, Silva MSR, Miranda SAF, Pascoaloto D, Santos HMC. Efeitos da ação antrópica sobre a hidrogeoquímica do rio Negro na orla de Manaus/AM. Acta Amazonica. 2009;39(3):627-38. doi: 10.1590/S0044-59672009000300018

70. Dias CA, Costa ASV, Guedes GR, Umbelino GJM, Sousa LG, Alves JH, et al. Impactos do rompimento da barragem de Mariana na qualidade da água do rio Doce. Rev Espinhaço. 2018;7(1):21-35.

71. Pereira BWF, Maciel MNM, Oliveira FA, Alves MAMS, Ribeiro AM, Ferreira BM, et al. Uso da terra e degradação na qualidade da água na bacia hidrográfica do rio Peixe-Boi, PA, Brasil. Rev Ambient Água. 2016 Apr/Jun;11(2):472-85. doi: 10.4136/ambi-agua.1802

72. Bertossi APA, Cecílio RA, Neves MA, Garcia GO. Qualidade da água em microbacias hidrográficas com diferentes coberturas do solo no sul do Espírito Santo. Rev Árvore. 2013;37(1):107-17. doi: 10.1590/S0100-67622013000100012

73. Fernandes MM, Ceddia MB, Ramos GM, Gaspar A, Moura MR. Influência do uso do solo na qualidade de água da microbacia Glória, Macaé - RJ. Engenharia Ambiental. 2011 Apr/Jun;8(2):105-16.

74. Gardiman Júnior BS, Simoura LT. Cobertura florestal e qualidade da água na bacia hidrográfica do rio Jucu, estado do Espírito Santo, Brasil. Sci Plena. 2016;12(1):1-15. doi: 10.14808/sci.plena.2016.010201

75. Silva DML, Camargo PB, McDowell WH, Vieira I, Salomão MSMB, Martinelli LA. Infuence of land use changes on water chemistry in streams in the State of São Paulo, southeast Brazil. An Acad Bras Ciênc. 2012;84(4):919-30. doi: 10.1590/S0001-37652012000400007 
76. Souza MM, Gastaldini MCC. Avaliação da qualidade da água em bacias hidrográficas com diferentes impactos antrópicos. Eng San Ambient. 2014 Jul/Sep;19(3):263-74. doi: 10.1590/S141341522014019000001097

77. Silva MSR, Miranda SAF, Santana GP. Bacia Hidrográfica do Rio Amazonas: Condições de suas águas versos Resolução No 357/CONAMA/2005. Sci Amazonia. 2016;6(2):83-90.

78. Belém FL, Cabral JBP. Dinâmica da paisagem na bacia hidrográfica da Usina Hidrelétrica de Ferreira Gomes - Amapá, Brasil. Caderno Geografia. 2019;29(56):119-33. doi: 10.5257/p.23182962.2019v29n56p119

79. Miranda RG, Pereira, SFP, Alves DTV, Oliveira GRF. Qualidade dos recursos hídricos da Amazônia Rio Tapajós: avaliação de caso em relação aos elementos químicos e parâmetros físico-químicos. Rev Ambient Água. 2009;4(2):75-92. doi: 10.4136/ambi-agua.88

80. Callegari-Jacques SM. Bioestatística: princípios e aplicações. Porto Alegre (RS): Artmed; 2003.

81. Santos GO, Hernandez FBT. Uso do solo e monitoramento dos recursos hídricos no Córrego do Ipê, Ilha Solteira, SP. Rev Bras Eng Agríc Ambiental. 2013;17(1):60-8. doi: 10.1590/S141543662013000100009

82. Jolliffe LT. Principal component analysis. 2. ed. Nova York (US): Springer; 2002.

83. Bargués-Tobella A, Reese H, Almaw A, Bayala J, Malmer A, Laudon H, et al. The effect of trees on preferential flow and soil infiltrability in an agroforestry parkland in semiarid Burkina Faso. Water Resour Res. 2014;50:3342-54. doi: 10.1002/2013WR015197

84. Garcia-Prats A, Del Campo AD, Pulido-Velazquez M. A hydroeconomic modeling framework for optimal integrated management of forest and water. Water Resour Res. 2016;52:8277-94. doi: 10.1002/2015WR018273

85. Ilstedt U, Bargués-Tobella A, Bazié HR, Bayala J, Verbeeten E, Nyberg G, et al. Intermediate tree cover can maximize groundwater recharge in the seasonally dry tropics. Sci Rep. 2016;6(e21930):1-12. doi: $10.1038 /$ srep21930 